splenic flexure or vice versa, how much more susceptible to injury the spleen will be when its architecture has been disrupted and weakened by a disease. Thus an everyday occurrence, such as coughing, bending or sneezing would be likely to initiate a tear in the splenic capsule. Such a physiological event may not be remembered by the patient, let alone recorded by the clinician so that it would seem to be preferable when the spleen is diseased, to avoid the use of the term 'spontaneous'. This is not to deny that truly spontaneous rupture of the diseased spleen occurs, but to stress the difficulty in differentiating between this and rupture of a diseased, parlously intact spleen, precipitated by minor stress which would have no effect on a normal spleen. Walton (1963) suggests the description 'pathological rupture' in these circumstances.

The aetiology of splenic rupture in leukaemia and the reticuloses in the absence of trauma may depend on one or more factors. Firstly, defects in blood coagulability must play a part. The patient reported had already bled spontaneously into the kidneys, skin and intestine and so it can be appreciated how a haematoma could have developed and subsequently ruptured through the splenic capsule. Secondly, if the splenic capsule is distended and infiltrated by a leukaemic or lymphomatous process then rupture is likely, particularly if there are adhesions to the bowel and diaphragm, which may be stretched by peristalsis and respiration. Lastly, infarction of the spleen may occur in leukaemia and the reticuloses with consequent rupture.

\section{Acknowledgments}

This patient was under the care of Dr Paget Davies ard Mr A. E. Stevens and I am grateful to them for their helpful criticism in the preparation of this paper.

\section{References}

Hynes, H.E., Silverstein, M.N. \& Fawcett, K.J. (1964) Spontaneous rupture of the spleen in acute leukaemia: report of 2 cases. Cancer, 17, 1356.

NaIberg, D., Sidlofsky, S. \& Chris, S.M. (1965) Spontaneous rupture of the spleen. Can. J. Surg. 8, 96.

Orloff, M.J. \& Peskin, G.W. (1958) Spontaneous rupture of the normal spleen-a surgical enigma. Int. Abstr. Surg. 106, 1 .

Stiles, T.B. \& UltmanN, J.E. (1966) Spontaneous rupture of the spleen in chronic lymphocytic leukaemia. Cancer, $19,1587$.

Walton, T.T. (1963) Splenic rupture in infectious mononucleosis. Texas J. Med. 59, 333.

\title{
Spontaneous rupture of the spleen in the prodromal period of chickenpox
}

\author{
HaziQ ul YaQIN \\ B.Sc., M.B., B.S., F.R.C.S., F.R.C.S.E. \\ Surgical Registrar, \\ Stoke Mandeville Hospital, Aylesbury
}

SPONTANEOUS rupture of the spleen is a rare surgical emergency but is a known hazard of pathological splenomegaly. It can occur in patients with an apparently normal spleen (Susman, 1927; Coleman, 1939; Orloff \& Peskin, 1958; Brodman \& Bautista, 1959).

Since Atkinson's report in 1874 a large number of cases of spontaneous rupture of the spleen have been described. It has occurred in malaria, kala-azar, infectious mononucleosis, typhoid, leukaemia and typhus; and less commonly in portal thrombosis, splenic infarct, Hodgkin's disease, splenic abscess, Banti's disease, relapsing fever, puerperal sepsis, pneumonia and certain other acute infective conditions.

This report describes spontaneous rupture of the spleen occurring in a young adult male who was suffering from prodromal chickenpox. A thorough search of the literature has failed to reveal any record of a similar case.

\section{Case report}

The patient, a 25-year-old warehouseman, was admitted to hospital as an emergency on 27 March 1968. Previous to this episode of illness, he was in good health and at full work.

On admission he complained of severe lower abdominal pain associated with nausea of $10 \mathrm{hr}$ duration. A day prior to his admission to the hospital he felt feverish and had backache and did not go to work. At 03.00 hours on the day of admission he was awakened by very severe generalized abdominal pain. This pain was accompanied by severe nausea and retching, but the patient did not 
vomit. During the day, the pain remained constant and severe and was now more marked in the lower abdomen, particularly in the right side. There was no radiation or referred pain.

On examination the patient was in obvious pain but his general condition was good. The tongue was thickly coated and foetor was present. No jaundice or undue pallor was noticed. There was no lymphadenopathy, skin rashes or oedema. Pulse was regular, $100 / \mathrm{min}$, temperature $100^{\circ} \mathrm{F}$ and blood pressure $130 / 70 \mathrm{mmHg}$. Apart from tachycardia the cardio-vascular and respiratory systems were normal.

Abdominal examination revealed generalized guarding and tenderness but this was more marked in the right lower abdomen where some rigidity was also noted. Rebound tenderness was present in both iliac fossae and the bowel sounds were normal. Rectal examination was painful on pressure on both lateral walls.

Hb $13.2 \mathrm{~g} / 100 \mathrm{ml}$, WBC $4000 / \mathrm{mm}^{3}$.

The family history revealed that his 5 -year-old son had recovered from chickenpox a fortnight previously.

A diagnosis of perforated appendicitis with peritonitis was made.

Operative findings: The abdomen was opened through a right grid-iron incision and on opening the peritoneum dark blood gushed out of the wound. The incision was closed and the abdomen was reopened through a right paramedian incision. The peritoneal cavity was found to be full of clotted blood. This was removed and the abdominal organs were inspected. An inch-long tear was found on the visceral surface of the lower pole of a normal-looking spleen. All the other organs were carefully scrutinized and no other abnormality was found. The spleen was removed. There were no adhesions between the spleen and diaphragm and the spleen appeared normal in size and gross characteristics. The abdomen was closed and the left sub-phrenic space drained. Blood loss was replaced by 1 litre of blood at operation at the end of which the patient's condition was satisfactory.

Although his immediate post-operative condition was satisfactory, he failed to improve and appeared generally ill. There was some slight blood loss from the drainage tube but this was insufficient to account for his condition. The possibility of a spontaneous rupture of a diseased spleen was considered and the following investigations carried out:

Hb $12.5 \mathrm{~g} / 100 \mathrm{ml}$, WBC $9000 / \mathrm{mm}^{3}$; Film showed occasional atypical mononuclear cells; prothrombin efficiency $56 \%$; platelets $85,000 / \mathrm{mm}^{3}$; Kaolincephalin test-normal; Schneider test-normal, titre 1:250; alkaline phosphatase 7.5 K.A. units; thymol turbidity 0.8 units; bilirubin $1.1 \mathrm{mg} / 100 \mathrm{ml}$; albumin $4.0 \mathrm{~g} / 100 \mathrm{ml}$; globulin $2.0 \mathrm{~g} / 100 \mathrm{ml}$; SGPT
35 units; sodium $110 \mathrm{mEq} / 1$; potassium $4,4 \mathrm{mEq} / 1$;⿳⺈ chloride $95 \mathrm{mEq} / 1 ; \mathrm{HCO}_{3}{ }^{-} 24 \mathrm{mEq} / 1$; Paul-Bunnell test-negative, serum titre $1: 7$.

On the 2 nd post-operative day he developed $a c$ generalized rash involving the trunk and both axillae. $\overrightarrow{\vec{F}}$ This was accompanied by moderate pyrexia. In view of the history of contact, a firm diagnosis of $\frac{-}{0}$ chickenpox was made. The patient was treated $\overline{\bar{\omega}}$ symptomatically and the rest of the post-operative period was uneventful. He was discharged home fully recovered with a healed wound 2 weeks later. $\$$

Pathology: 'Spleen $15 \times 9 \times 5 \mathrm{~cm}$. There is a point $\overrightarrow{0}$ of recent rupture on the inferior border near thelower pole $1 \mathrm{~cm}$ long. Section across this slightly. enlarged spleen shows soft pale congested centre.' $\bar{D}$

Histology: 'The spleen shows a marked congestion of the pulp with a slight diminution in size of the lymph follicles. There is a proliferation of the lining cells of the sinuses and some of these cells appear larger than normal as though in the process of ${ }^{6}$ becoming mononuclear histiocytes. There is also an increase in the size of and possibly number of the reticulum cells. Some of these larger cells show what ${ }_{c}^{-}$ appears to be possibly intra-nuclear inclusion bodies. ٍ There is a moderate amount of infiltration of the pulp by polymorphonuclear leucocytes with a fewe eosinophils. There are very occasional small giamt $\vec{c}$ cells with about three nuclei. The general back ground change in the walls of the sinuses on to whole favours a virus type of infection.'

The patient was seen 4 weeks after his discharge from the hospital when he was in good health. Theo following further investigations were carried out to exclude any known condition in which spontaneous $\cong$ rupture has been recorded:

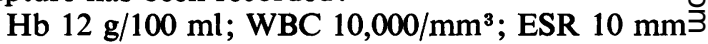
in $1 \mathrm{st} \mathrm{hr}$; platelets $470,000 / \mathrm{mm}^{3}$; film showed some iron deficiency target cells. Repeat liver function? tests were within normal limits; Widal, negative; titre $1: 30$; sternal marrow was reported as normal.

Complement fixation test for varicella, negative; titre $1: 32$.

\section{Discussion}

Spontaneous rupture of the spleen is an extremely응 difficult condition to diagnose before laparotomy $\frac{7}{0}$ Orloff \& Peskin (1958) made an extensive survey of all the cases of spontaneous rupture of the normal spleen and showed that out of twenty-eight authenticated cases, only in one was a pre-operative diagnosis of ruptured spleen considered.

Hershey \& Lubitz (1948) reviewed sixty-four cases of spontaneous rupture of malarial spleens reported in the literature since 1917 and found that the correct diagnosis was made only in seven patients.

Other authors (Susman, 1927; Colman, 1939; 꿍 Rankin, 1939; Moore \& Chapman, 1951; Nicoll, 
1952; Thompson, 1954; Brodman \& Bautista, 1959) emphasize the diagnostic difficulties in such cases and in none of their patients was a correct diagnosis made prior to operation.

In this case, in view of the operative findings both the patient and his wife were questioned on several occasions but no history of recent or remote injury could be obtained nor did the patient suffer from any previous disease which could have given rise to a pathological spleen liable to rupture.

The following points are of interest in this patient:

(1) There was no pre-operative clinical evidence of excessive loss of blood and in spite of the serious nature of the disease the patient's initial physical condition did not suggest this.

(2) The predominant symptoms were pain in the lower abdomen and there was a complete absence of signs of diaphragmatic irritation or of classical haemo-peritoneum.

(3) Histological appearance of the spleen suggested a viral type of infection.

\section{Acknowledgments}

I wish to thank Mr G. J. Hadfield for allowing me to manage and report this case and for his constant encouragement and advice. I also wish to thank Dr C. S. Pitcher for advice and carrying out all the haematological tests and Dr H. J. Harris for reporting on the pathology of the spleen. Serum varicella complement fixation test was done by $\mathrm{Dr}$ A. H. Tomlinson of the Radcliffe Infirmary, Oxford, for which I am grateful.

\section{References}

Albuquerque, D.B. (1966) Spontaneous rupture of the spleen complicating infectious mononucleosis. J. Indian med. Ass. 46, 562.

Aronson, W. \& Fox, R.A. (1940) Spontaneous rupture of pathologic spleen. Amer. J. clin. Path. 10, 868.
AtKinson, E. (1874) Death from idiopathic rupture of spleen. Brit. med. J. ii, 403.

Brodman, H.R. \& Bautista, J. (1959) Spontaneous rupture of the normal spleen. Arch. Surg. 78, 406.

Coleman, A.H. (1939) Spontaneous rupture of the normal spleen. Brit. J. Surg. 27, 173.

Cooray, G.H. (1952) Spontaneous rupture of a leukaemic spleen. Brit. med. J. i, 693.

Flood, M.J. \& Carpenter, R.A. (1961) Spontaneous rupture of the spleen in acute myeloid leukaemia. Brit. med. $J$. i, 35.

Goldstein, H.S. (1966) Spontaneous rupture of the spleen secondary to metastatic carcinoma. South. med. J. 59, 261.

Hennequin, J.P., Geoffroy, A. \& Wilheim, J. (1965) Ruptures traumatiques et spontanées de la rate. Ann. med. Nancy, 4, 985.

Hershey, F.B. \& Lubitz, J.M. (1948) Spontaneous rupture of malarial spleen. Ann. Surg. 127, 40.

KNAUER, Q.F. \& Abrams, J.S. (1966) Generalised peritonitis due to a ruptured splenic abscess. Amer. J. Surg. 112, 923.

KNOBLiCH, R. (1966) Pathologic (so called spontaneous) rupture of the spleen in leukemia and lymphoma. Michigan Med. 65, 105.

Moore, J.A. \& ChAPMAN, J.P. (1951) Spontaneous rupture of the spleen. Ann. Surg. 17, 540.

Nicoll, J.A.V. (1952) Spontaneous rupture of the spleen. Brit. med. J. i, 801.

Orloff, M.J. \& Peskin, G.W. (1958) Spontaneous rupture of the normal spleen. A surgical enigma. Inst. Obst. Surg. 106, 1.

RANKIN, L.M. (1939) Rupture of the spleen from muscular action. Amer. J. Surg. 45, 598.

Susman, M. (1927) Spontaneous rupture of the spleen. Brit. J. Surg. 15, 47.

Thомpson, B.A. (1954) Spontaneous rupture of the spleen. Brit. med. J. ii, 1209.

WoHL, M.G. (1925) Spontaneous rupture of the spleen. Ann. Surg. 82, 246.

Yurko, A.A., Winegarner, F.G. \& Kinsey, D.L. (1965) The danger of ruptured spleen in infectious mononucleosis. Ohio Med. J. 61, 994. 